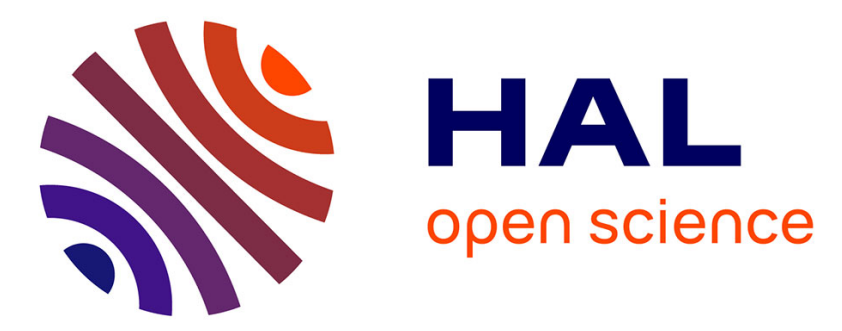

\title{
Thermal and radio-oxidation of epoxy coatings
}

\author{
C Galant, Bruno Fayolle, Matthias Kuntz, Jacques Verdu
}

\section{To cite this version:}

C Galant, Bruno Fayolle, Matthias Kuntz, Jacques Verdu. Thermal and radio-oxidation of epoxy coatings. Progress in Organic Coatings, 2010, 69 (4), pp.322-329. 10.1016/j.porgcoat.2010.07.005 . hal-02458293

\section{HAL Id: hal-02458293 \\ https://hal.science/hal-02458293}

Submitted on 28 Jan 2020

HAL is a multi-disciplinary open access archive for the deposit and dissemination of scientific research documents, whether they are published or not. The documents may come from teaching and research institutions in France or abroad, or from public or private research centers.
L'archive ouverte pluridisciplinaire HAL, est destinée au dépôt et à la diffusion de documents scientifiques de niveau recherche, publiés ou non, émanant des établissements d'enseignement et de recherche français ou étrangers, des laboratoires publics ou privés. 


\title{
Thermal and radio-oxidation of epoxy coatings
}

\author{
C. Galant ${ }^{\mathrm{a}, \mathrm{b}}$, B. Fayolle ${ }^{\mathrm{b}, *}$, M. Kuntz ${ }^{\mathrm{c}}$, J. Verdu ${ }^{\mathrm{b}}$ \\ a EDF - Direction Production Ingénierie/SEPTEN, Division Réacteur Nucléaire et Echangeurs, 12-14 avenue Dutriévoz, 69628 Villeurbanne Cedex, France \\ b PIMM, UMR 8006 CNRS - Arts et Métiers ParisTech 151, Bd de l'Hôpital, 75013 Paris, France \\ ${ }^{\mathrm{C}}$ EDF RE'D, Département Matériaux et Mécanique des Composants, Avenue des Renardières, Ecuelles, 77250 Moret sur Loing, France
}

Keywords:

Epoxy coatings

Oxidation

Glass transition

Chain scission

\section{A B S T R A C T}

Degradation induced by thermal $\left(50-110^{\circ} \mathrm{C}\right)$ and radio-oxidation of low $T_{g}$ epoxy-amine networks has been studied. It has been found that oxidation leads mainly to amide groups formation at the vicinity of tertiary amines whatever ageing conditions (thermal or radio-oxidation at $200 \mathrm{~Gy} \mathrm{~h}^{-1}$ ). In addition, some species as acids, peracids or formates have been revealed indicating a chain scission process. Physical modifications as $T_{g}$ decrease and soluble fraction increase due to chain scission process, have been correlated with chemical modifications.

\section{Introduction}

Epoxy networks are widely used as coatings in various industrial domains. The specific constraints of coating applications lead to use aliphatic hardeners of relatively high reactivity to perform the cure at ambient temperature, and to limit the glass transition temperature $\left(T_{g}\right)$ values to about $60-80^{\circ} \mathrm{C}$ in order to benefit of a certain ductility and a relatively high thermal expansivity. These constraints limit the number of possible epoxide-amine combinations. The most common family of networks fulfilling these conditions is based on diglycidyl ether of bisphenol A(DGEBA)-polyamidoamine (PAA) oligomers. The adequate $T_{g}$ value is obtained thanks to the high flexibility of the polyamide chain, the possibility to modulate the length of both DGEBA and PAA and to adjust the crosslink density by varying the amine/epoxide functional ratio. This type of coating is abundantly used in nuclear plants where ageing induced embrittlement can be critical, that justifies the interest of research workers in this topic.

It is well recognized that, for networks of this family, long term ageing is mainly dominated by oxidative degradation resulting from a radical chain mechanism. In the case of nuclear plants applications, two chain initiation processes coexist: radiochemical initiation (RI) resulting mainly from polymer radiolysis and thermal initiation (TI) resulting mainly from hydroperoxide decomposition. According to Khelidj et al. [1], RI must predominate at high dose rates and TI at low dose rates. At predominant RI, oxidation products are expected to grow almost proportionally to the exposure

\footnotetext{
* Corresponding author. Tel.: +3314424 6149; fax: +33144246382

E-mail address: bruno.fayolle@paris.ensam.fr (B. Fayolle).
}

time, whereas at predominant TI, oxidation kinetics are expected to display an induction period, a strongly auto-accelerated character and a dependence on temperature and antioxidants considerably more marked than with RI. In the absence of experimental data, there is no way to determine the respective parts of RI and TI in ageing kinetics. This is the reason why we propose here to compare radiochemical ageing at relatively high dose rate $\left(200 \mathrm{~Gy} \mathrm{~h}^{-1}\right)$ with thermal ageing at temperatures ranging from 50 to $110^{\circ} \mathrm{C}$.

Literature on epoxy oxidative ageing is relatively abundant, but the number of articles remains low compared to the diversity of network structures so that there is a limited knowledge on a given structure. DGEBA-amine systems have, however, in common the i-propanol moiety:<smiles>COCC(O)CN(C)C</smiles>

In this moiety, each $\mathrm{CH}$ bond is in $\alpha$ of an electronegative atom ( $\mathrm{O}$ or $\mathrm{N})$, that decreases its dissociation energy and increases its reactivity in radical chain propagation. It appears thus as a "weak point" in the network structure, responsible for some common features of the oxidation processes in DGEBA networks. These common features are for instance: gas evolution $\left(\mathrm{H}_{2}, \mathrm{CO}, \mathrm{CO}_{2}, \mathrm{CH}_{4}\right.$, etc.) [2-4]; carbonyl growth [3-6], chain scission [5,7-11], double bond formation $[3,4,12]$ and amide formation $[5,12-15]$. It remains difficult, however, to predict from these results the behaviour of new systems on which no fundamental data are available. This is apparently the case for epoxy coatings of the DGEBA-PAA type for which an unique paper [16] reports only results of thermogravimetry, $T_{g}$ variation, contact angle and adhesive strength, interesting for prac- 

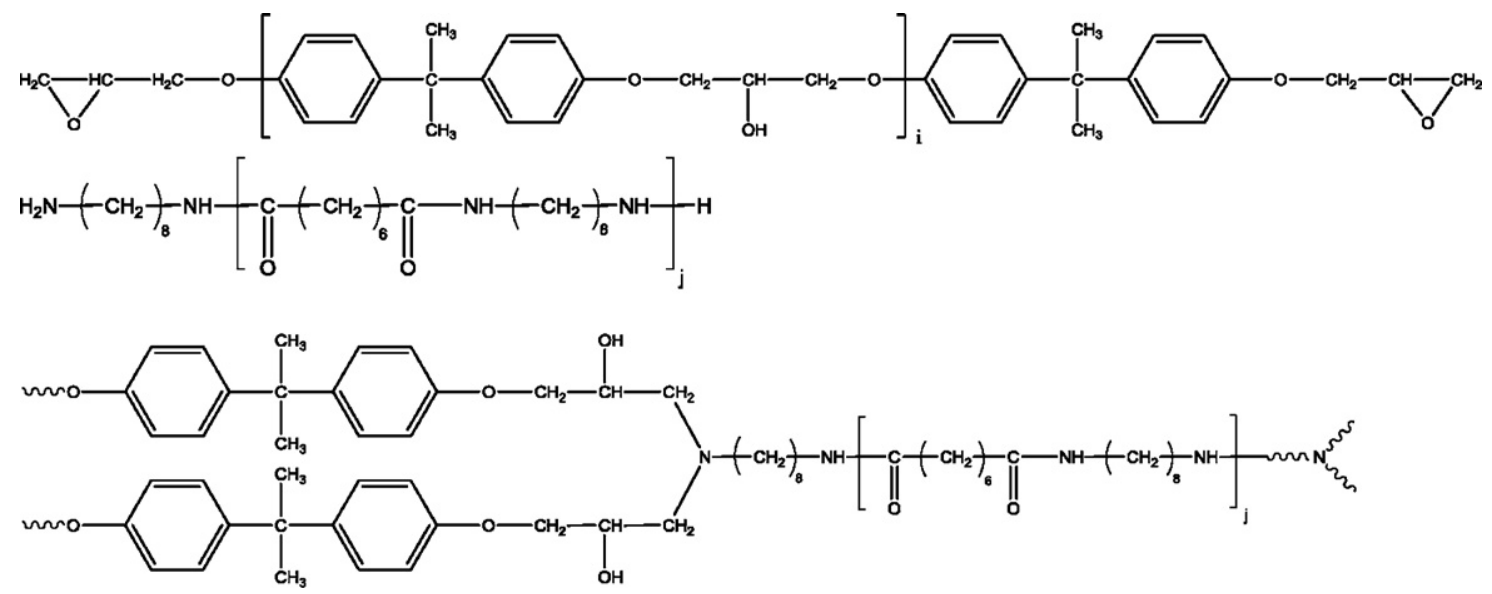

Fig. 1. Chemical structure of the studied network, $i$ and $j$ being the degree of polymerization for DGEBA and polyamidoamine, respectively.

titioners but impossible to connect with ageing mechanisms since the exact structure of the network is not reported.

The aim of this article is to report some results of thermal and radiochemical ageing of a relatively well defined DGEBA-PAA network combining spectrochemical (IR) and physical (DSC, sol-gel analysis) methods. The more or less remote objective is to collect data to elaborate a kinetic model aimed to predict the coating embrittlement in given exposure conditions.

\section{Experimental}

\subsection{Materials}

Epoxy-amine networks have been prepared from diglycidylether of bisphenol A (DGEBA) and a poly(amidoamine). The combination of several analytical techniques (proton and carbon NMR, steric exclusion chromatography, gas phase chromatography coupled with mass spectrometry) enabled us to identify the chemical structure of the used products, especially the average degree of polymerization of each unit. The chemical structures obtained from this identification are schematized in Fig. 1. Molar mass has been found close to $1170 \mathrm{~g} \mathrm{~mol}^{-1}$ (average degree of polymerization $i \sim 3$ ) for DGEBA and close to $1250 \mathrm{~g} \mathrm{~mol}^{-1}$ (average degree of polymerization $j \sim 3.9$ ) for the polyamidoamine. Before crosslinking process, fillers (among which $\mathrm{TiO}_{2}$ ) have been added; their content is equal to $29.5 \%$ in mass.

The reaction between the epoxy functions of DGEBA and amines of the hardener results in the formation of tridimensional network, with nitrogen atoms as network nodes (see Fig. 1). The stoichiometric ratio amine/epoxy has been chosen equal to 1.1. As a result, one can estimate the crosslink density $\left(v_{0}\right)$ at $1.08 \mathrm{~mol} \mathrm{~kg}^{-1}$ by using the following relationship assuming a complete epoxide-amine reaction and considering that all the tertiary amines work as crosslinks:

$v_{0}=\frac{n_{x}}{M_{\mathrm{NRU}}}=\frac{4}{2 M_{E}+r M_{A}}$

where $n_{x}$ is the crosslink number in the network repetitive unit in amine excess (NRU), $M_{\mathrm{NRU}}$ the molar mass of the network repetitive unit (see Fig. 1), $r$ the stoichiometric ratio, $M_{E}$ the molar mass of DGEBA and $M_{A}$ the molar mass of polyamidoamine.

For this study, test specimens were prepared by applying thin coats of paint (approximately $70 \mu \mathrm{m}$ thick per coat) on "concrete" substrates, of dimensions $200 \mathrm{~mm} \times 100 \mathrm{~mm} \times 50 \mathrm{~mm}$. Free films of each monolayer were also made, with thicknesses between 30 and $80 \mu \mathrm{m}$ to insure that thermal oxidation is not controlled by oxygen diffusion.

\subsection{Exposure conditions}

Thermal ageing was carried out in ventilated ovens at four temperatures $\left(50,70,90\right.$ and $\left.110^{\circ} \mathrm{C}\right)$ whereas irradiation was performed by using gamma radiation (source ${ }^{60} \mathrm{CO}$ ), with a dose rate of $200 \mathrm{~Gy} / \mathrm{h}$, at $50^{\circ} \mathrm{C}$ in air, thanks to SCKEN facilities (Belgium). After ageing, samples of coatings on "concrete" were then taken using a cutter blade, which gave to the final samples the appearance of a coarser powder allowing FTIR and DSC measurements (see below).

\subsection{Methods}

FTIR measurements were carried out using a Bruker IFS 28 spectrophotometer. The spectra were recorded between 4000 and $400 \mathrm{~cm}^{-1}, 64$ scans were averaged for a resolution of $4 \mathrm{~cm}^{-1}$. Pellets were made from a mixture of $\mathrm{KBr}$ powder and the sample to be analysed in transmittance mode. Free films have been analysed directly in transmittance mode.

For a given species, the concentration is determined from:

[species $]=\frac{\varepsilon_{\text {Ar }}[\mathrm{Ar}]_{\text {film }}}{\varepsilon_{\text {species }}} \frac{A(\text { species })}{A(\mathrm{Ar})}$

where $A$ (species) and $\varepsilon_{\text {species }}$ are the absorbance and the coefficient of molar extinction of the species, respectively. The aromatic peak at $1605 \mathrm{~cm}^{-1}\left(A(\mathrm{Ar}), \varepsilon_{\mathrm{Ar}}\right)$ is taken as internal standard. The product $\varepsilon_{\mathrm{Ar}}[\mathrm{Ar}]$ is expected to be independent of the sample geometry. It can be determined from transmittance measurements on films:

$\varepsilon_{\text {Ar }}[\operatorname{Ar}]_{\text {film }}=\frac{A(\operatorname{Ar})_{\text {film }}}{l_{\text {film }}}$

where $l_{\text {film }}$ is the film thickness. A $\mathrm{KBr}$ pellet is characterized by a given value of the aromatic peak absorbance. It is equivalent to a film of which the thickness would be given by Eq. (3). To assess amide concentration, coefficient of molar extinction $\varepsilon_{\text {amide }}$ has been chosen equal to $1380 \mathrm{~mol}^{-1} \mathrm{~cm}^{-1}$ according to [17].

In order to identify oxidation products, certain aged samples were treated with $\mathrm{NH}_{3}$ before being analysed a second time by FTIR. It is well known that ammonia reacts with certain oxidation products to form new products that may be identified by FTIR spectrophotometry $[12,18]$. For instance, $\mathrm{NH}_{3}$ reacts with carboxylic acids to form ammonium carboxylates which absorb at $1580-1560 \mathrm{~cm}^{-1} . \mathrm{NH}_{3}$ also reacts with formates to give formamides which absorb at $1690 \mathrm{~cm}^{-1}$. Finally, $\mathrm{NH}_{3}$ reacts with esters to form amides which absorb at $1680-1660 \mathrm{~cm}^{-1}$. On the other hand, $\mathrm{NH}_{3}$ does not react with cetones nor aldehydes.

DSC measurements were carried out using a Q10 instrument (TA Instruments) in a nitrogen flow with a flow rate of $50 \mathrm{ml} \mathrm{min}^{-1}$. 

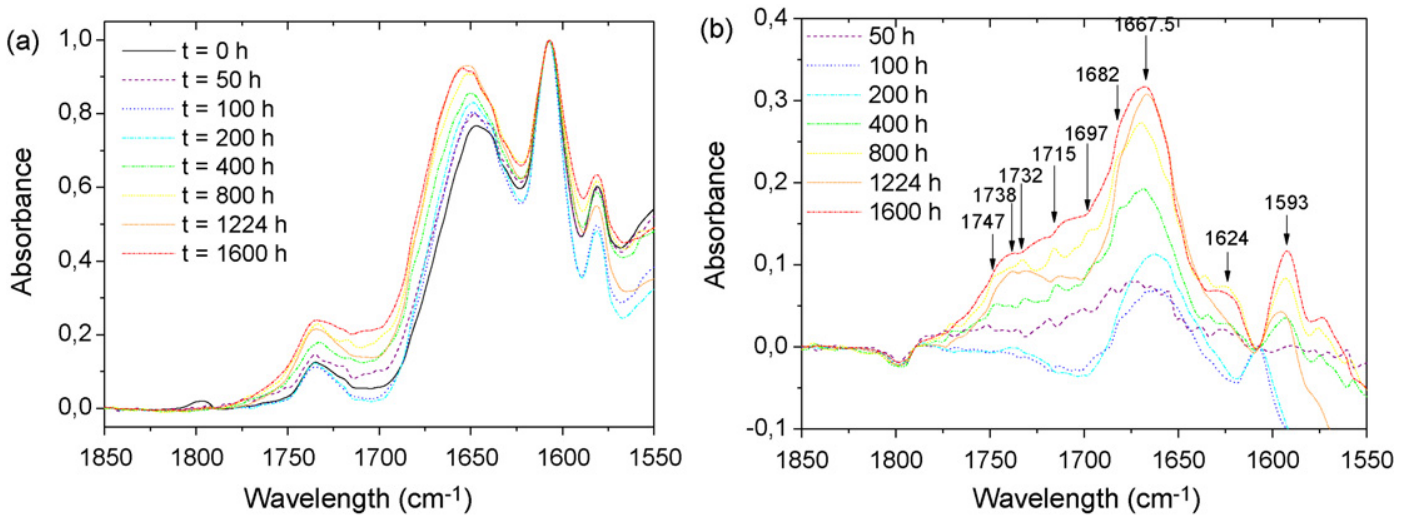

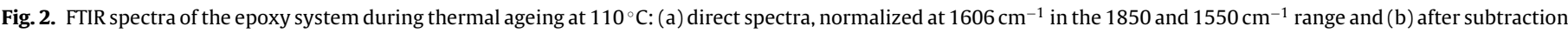
of the initial sample spectrum.

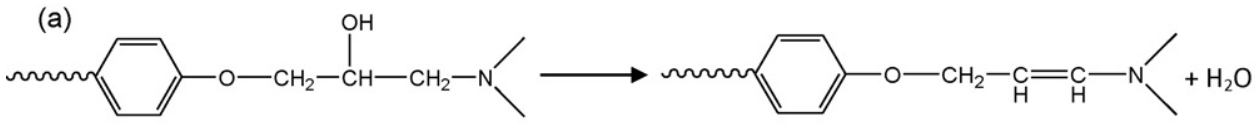

(b)

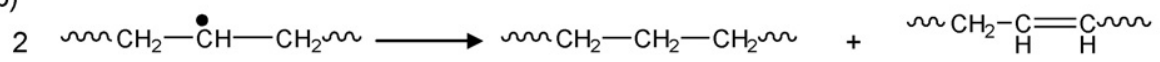

Fig. 3. Possible pathways for double bond formation.

After an initial temperature rise from -50 to $150^{\circ} \mathrm{C}$, at $10^{\circ} \mathrm{C} / \mathrm{min}$, cooling to $20^{\circ} \mathrm{C} / \mathrm{min}$ was applied, followed by a second temperature rise identical to the first one. The free films were subjected to a run including an initial temperature rise from -20 to $150^{\circ} \mathrm{C}$, at $10^{\circ} \mathrm{C} / \mathrm{min}$, followed by cooling to $20^{\circ} \mathrm{C} / \mathrm{min}$ and second temperature rise from -20 to $150^{\circ} \mathrm{C}$, at $10^{\circ} \mathrm{C} / \mathrm{min}$. The initial temperature rise is used to remove water, without significant $T_{g}$ changes due to an eventual post curing. Accordingly, the $T_{g}$ of the materials is determined during the second temperature rise. Two to three temperature cycles per system and per exposure time/temperature or dose pair were carried out to check the reproducibility of the $T_{g}$ values.

Soluble fraction of samples (free films) was extracted in a soxhlet using tetrahydrofurane (THF). The films were first dried in a dessiccator for 1 week at room temperature, before being weighted then subjected to almost $12 \mathrm{~h}$ of extraction. The films were then dried for $48 \mathrm{~h}$ in free air before being stored in a dessiccator at room temperature. Their weight was then measured regularly until equilibrium was obtained. The final weight of the samples after extraction was determined after a final treatment of $24 \mathrm{~h}$ in an oven at $70^{\circ} \mathrm{C}$ (desorption of THF is thus considered as complete).

\section{Results and discussion}

\subsection{Chemical modifications during thermal ageing}

IR spectra obtained in standard conditions on a sample coated on concrete and aged in air at $100^{\circ} \mathrm{C}$ are shown in Fig. 2a. Changes can be observed in the $1750-1600 \mathrm{~cm}^{-1}$ region but band overlapping does not allow identifying the absorbing species. Clearer information can be obtained by subtracting the initial spectrum from the spectra of aged samples [3] (Fig. 2b). The spectral changes are mainly located in three relatively sharp intervals corresponding presumably to three distinct species:

- Double bonds close to $1600 \mathrm{~cm}^{-1}$ (bands at 1624 and $1593 \mathrm{~cm}^{-1}$ ).

- Amides at $1667 \mathrm{~cm}^{-1}$ (predominant species).<smiles>CCCCCCCC(O)CC(O)C(=O)N(C)C</smiles>

Fig. 4. Presumed way for amide formation during oxidation.

- Carbonyls at $1730 \pm 30 \mathrm{~cm}^{-1}$ (wide band from multiple overlappings).

Two distinct pathways can be imagined for double bond formation. The dehydration of the i-propanol unit in the DGEBA segments (Fig. 3a) or the disproportionation of alkyl radicals in the polymethylenic sequences belonging to polyamidoamine segments (Fig. 3b).

Concerning amide formation, it must be recalled that amides are initially present in the polyamidoamine segments. The only way to form new (and distinct) amides is an oxidation of amino methylenes in the vicinity of network nodes (Fig. 4).

Amide formation during oxidation of epoxide-amine networks has been observed by many authors [5,12-15]. The amide yield is correlated with electron density on the nitrogen atom, which is especially high in the case of aliphatic amines [19]. It is not surprising to observe that (tertiary) amides are the predominant oxidation product.

Carbonyl formation can result from various pathways. Oxidation of aliphatic polyamide segments can lead to imides, but also to aldehydes [3-6]. These latter are highly reactive and can be rapidly transformed into peracids and then acids (Fig. 5).

Carbonyls can also result from oxidation of alcohol and ether groups of the i-propanol unit belonging to the DGEBA moiety (Fig. 6).

Ammonia treatment is expected to transform esters into amides and acids into carboxylates $[12,18]$. The spectrum of a derivatized sample (after $800 \mathrm{~h}$ ageing at $110^{\circ} \mathrm{C}$ in air-Fig. 7a), reveals the disappearance of almost all the carbonyl containing species, showing that carboxylic groups predominated largely over carbonyl ones 


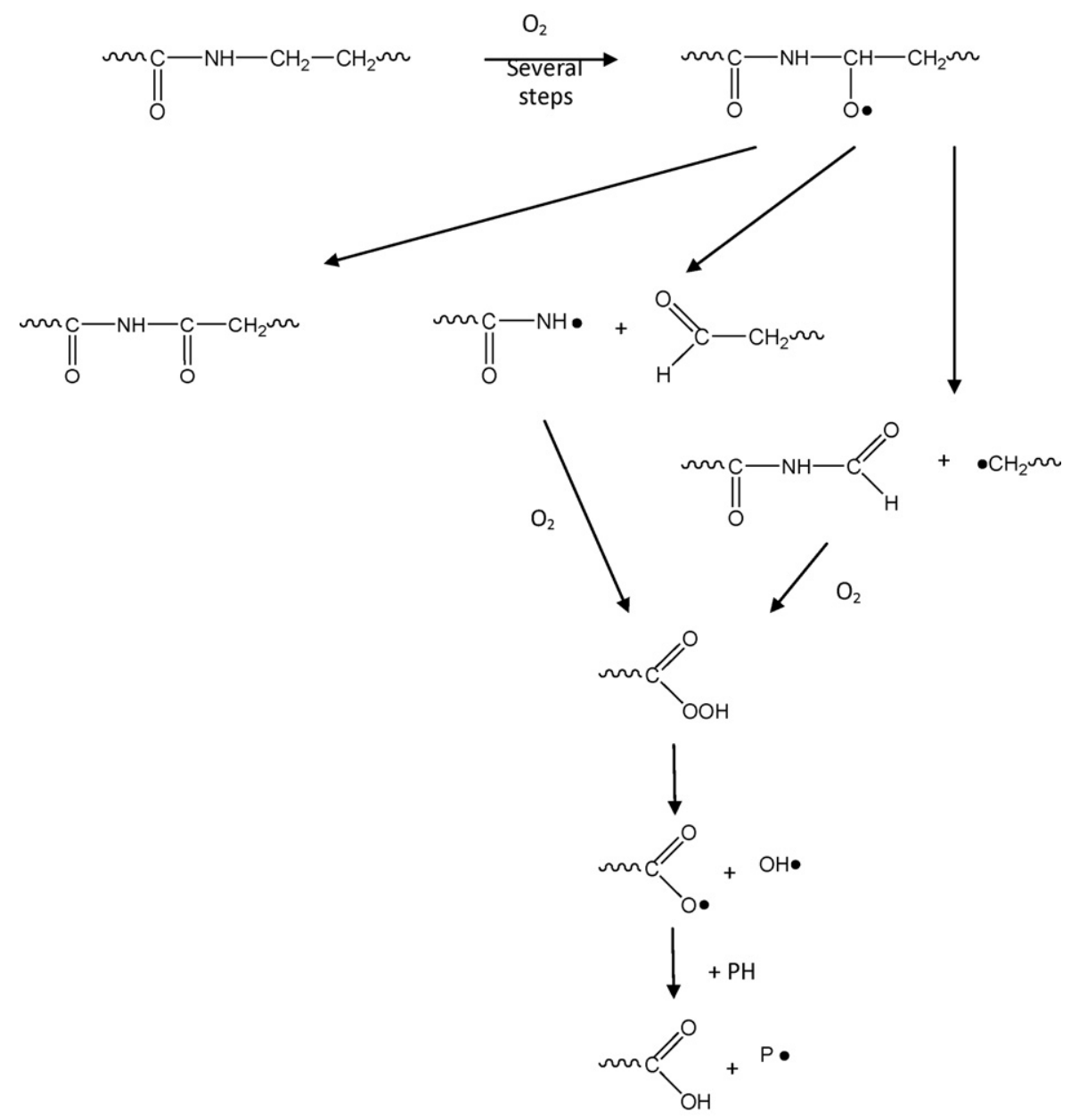

Fig. 5. Possible oxidation pathways for the polyamidoamine segments (PH: substrate; P•: alkyl radical).
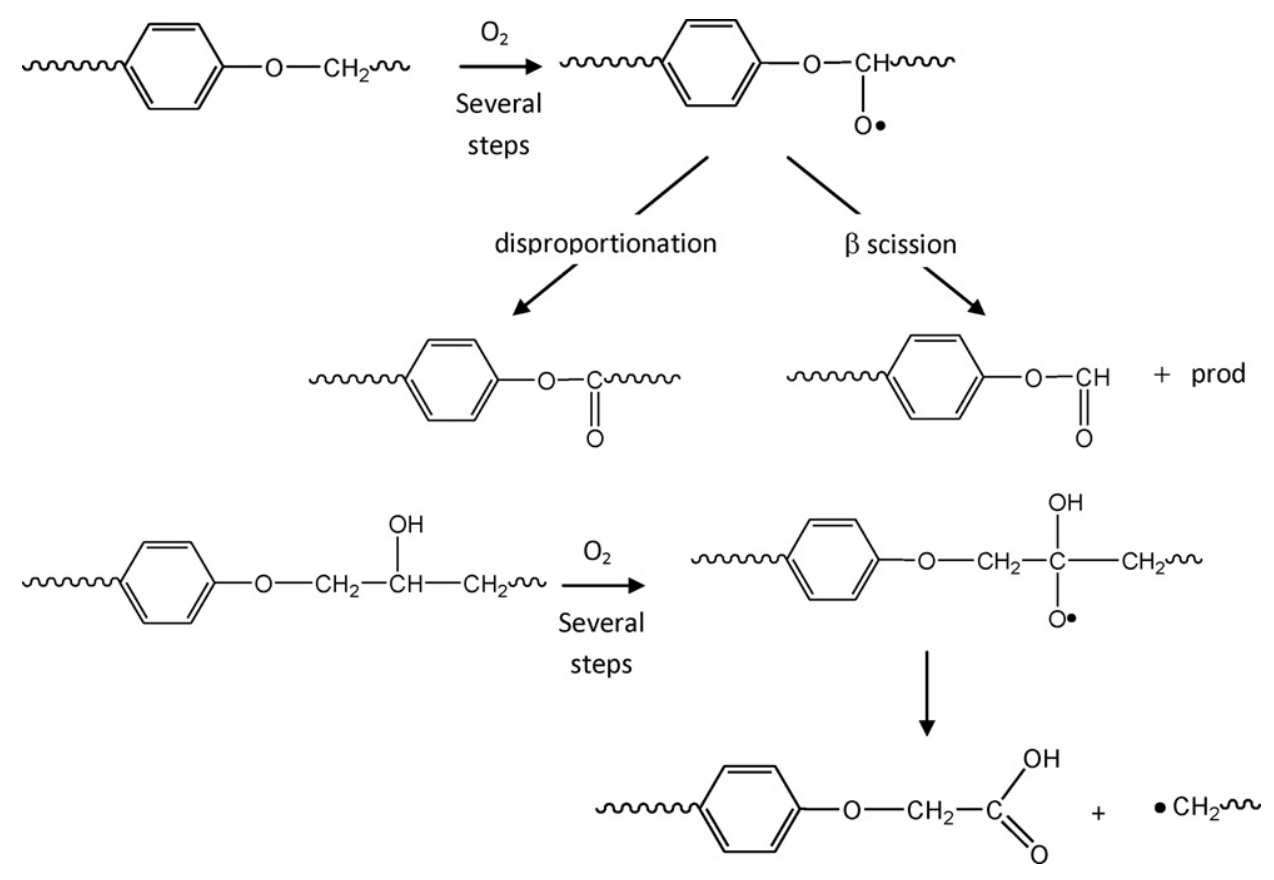

Fig. 6. Possible oxidation pathways for the i-propanol unit. 

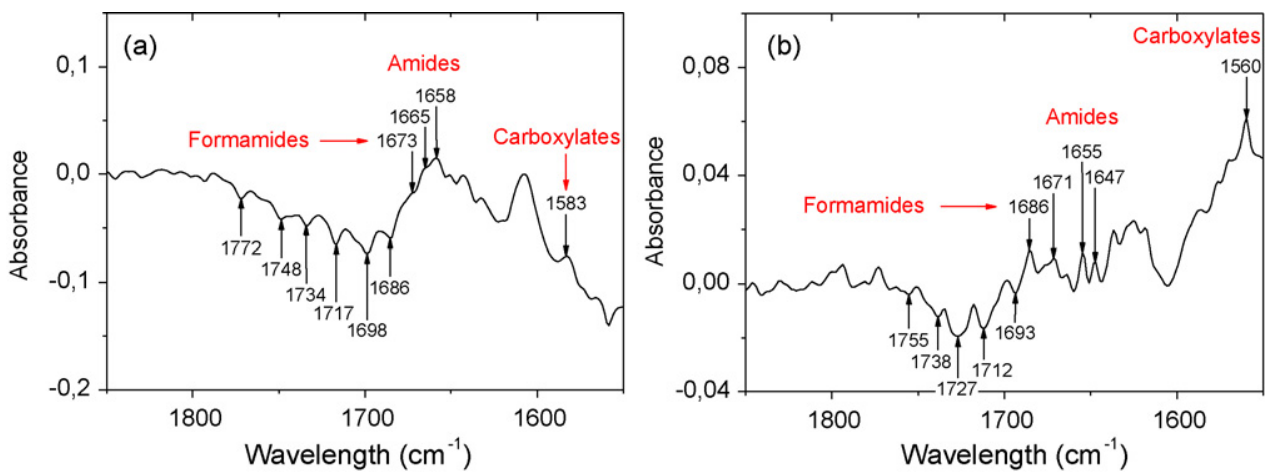

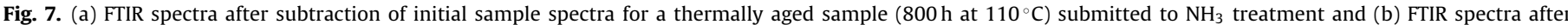
subtraction of initial sample spectra for an irradiated sample (absorbed dose of $80 \mathrm{kGy}$ ) submitted to $\mathrm{NH}_{3}$ treatment.
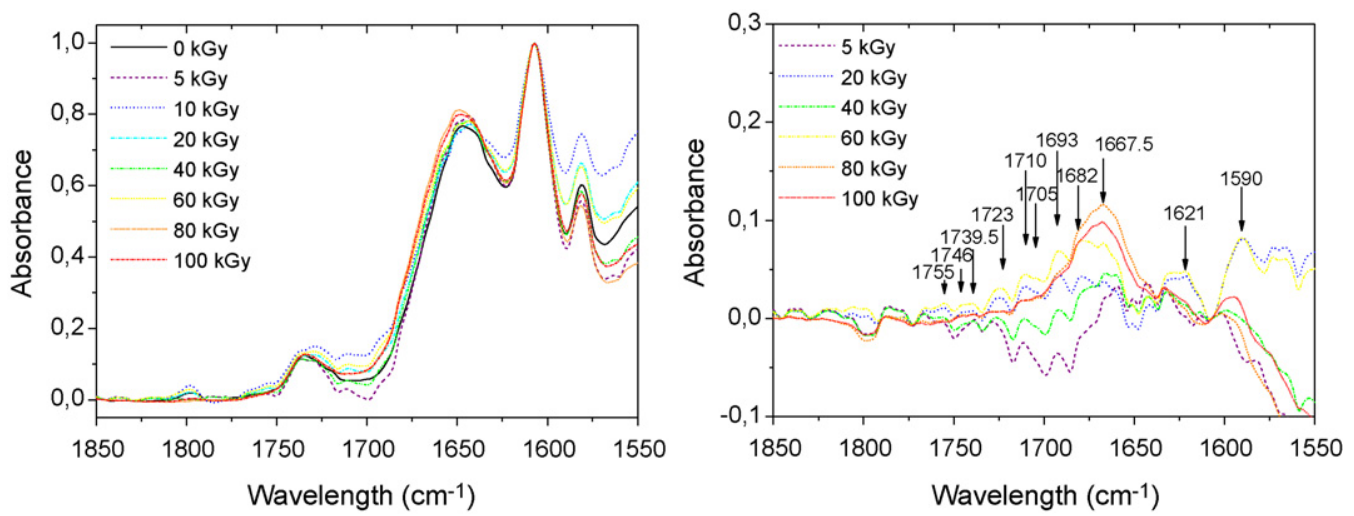

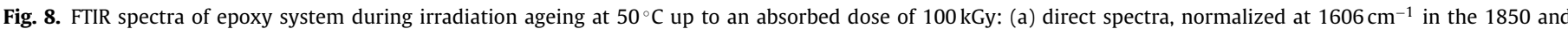
$1550 \mathrm{~cm}^{-1}$ range and (b) after subtraction of initial sample spectrum.
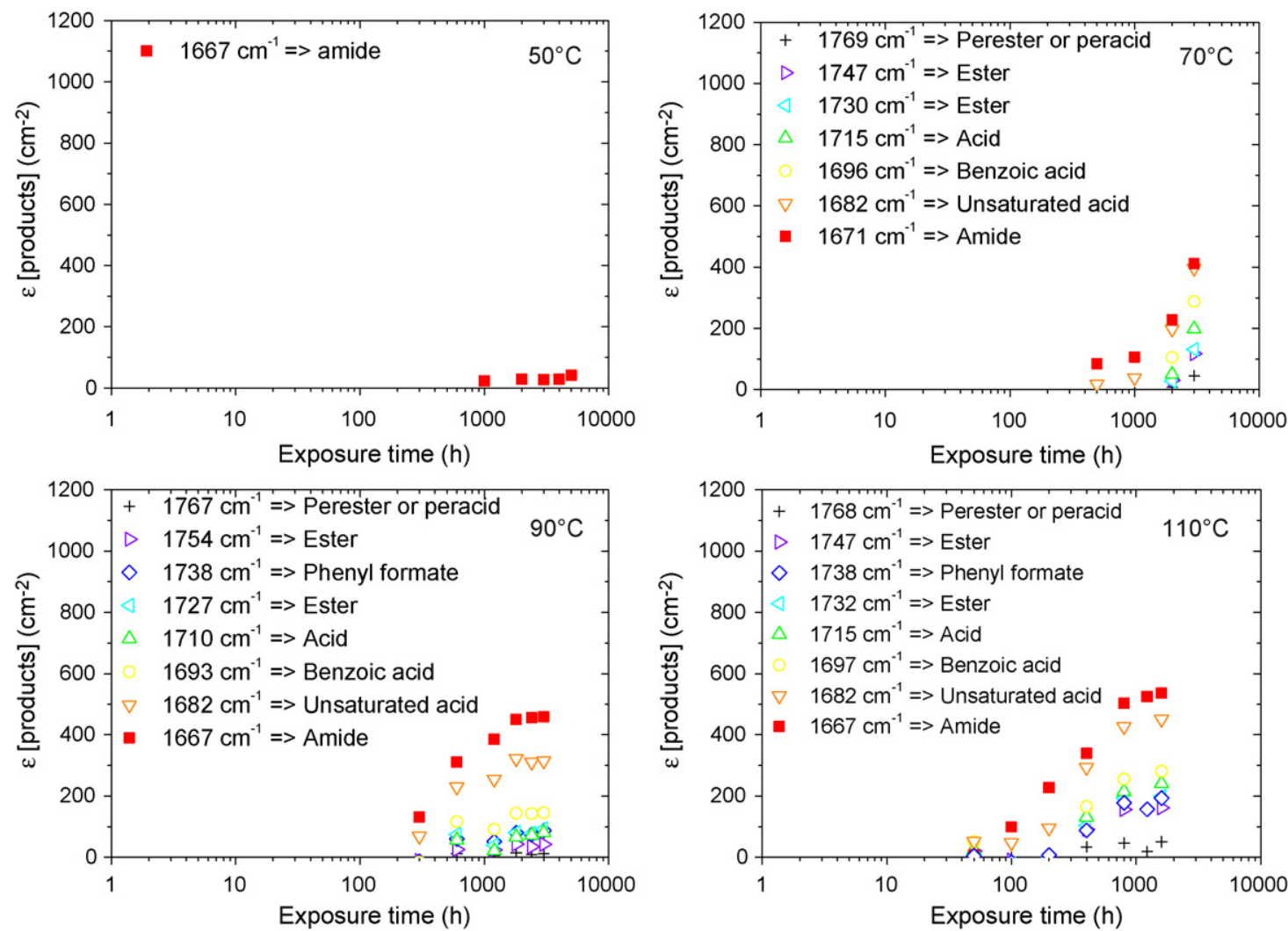

Fig. 9. Oxidation products build-up during thermal oxidation at $50,70,90$ and $110^{\circ} \mathrm{C}$ for epoxy samples on concrete. 


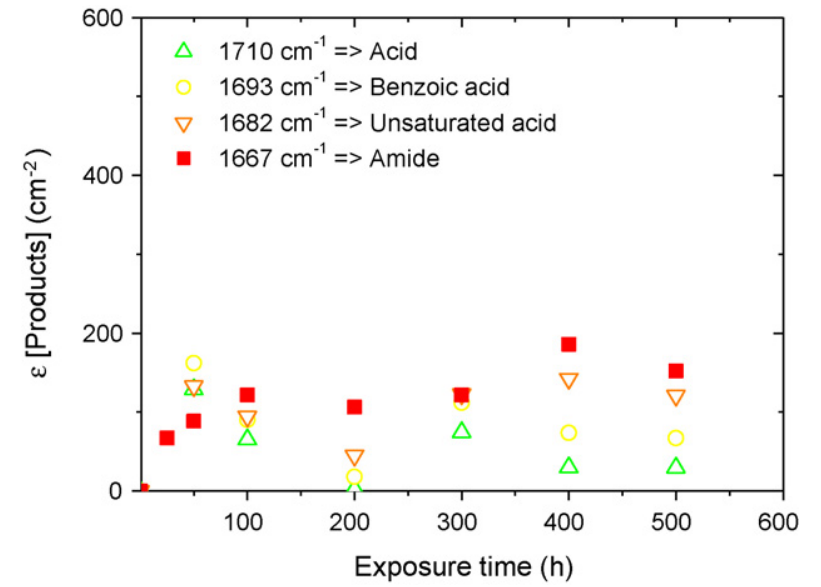

Fig. 10. Oxidation products build-up during irradiation for a dose rate of $200 \mathrm{~Gy} \mathrm{~h}^{-1}$ at $50^{\circ} \mathrm{C}$ for epoxy samples on concrete.

(ketones and aldehydes). Carboxylate $\left(1583 \mathrm{~cm}^{-1}\right)$ and formamide $\left(1673 \mathrm{~cm}^{-1}\right)$ appeared among other unidentified amide and imide groups. These results are consistent with the mechanisms proposed above.

\subsection{Chemical modifications during irradiation}

IR spectral changes induced by irradiation are shown in Fig. 8 . In the conditions under study (doses up to $100 \mathrm{kGy}$ at $50^{\circ} \mathrm{C}$ in air), the changes seem to be more important in the double bond region, especially at $1590 \mathrm{~cm}^{-1}$, and less important in the carbonyl region, especially above $1710 \mathrm{~cm}^{-1}$. Tertiary amides appear as the predominant oxygen containing product as for thermal ageing. Ammonia treatment does not bring supplementary information (Fig. 7b). The fact that the carbonyl/carboxyl yield seems comparatively lower during irradiation than during thermal ageing could be explained by the fact that carbonyls mainly result from hydroperoxide decomposition. This latter is expected to depend essentially on temperature with a relatively high activation energy (>80 $\mathrm{kJ} \mathrm{mol}^{-1}$ ) and to be almost independent of irradiation.

\subsection{Kinetics aspects}

Some kinetics curves of tertiary amide growth (at $1667 \mathrm{~cm}^{-1}$ ) during thermal ageing are shown in Fig. 9. They display an induction period of which the duration is higher than $1000 \mathrm{~h}$ at $50^{\circ} \mathrm{C}$, of the order of $200-300 \mathrm{~h}$ at $70^{\circ} \mathrm{C}$, about $100 \mathrm{~h}$ at $90^{\circ} \mathrm{C}$ and about $50 \mathrm{~h}$ at $110^{\circ} \mathrm{C}$. The auto-accelerated character of oxidation is attributed

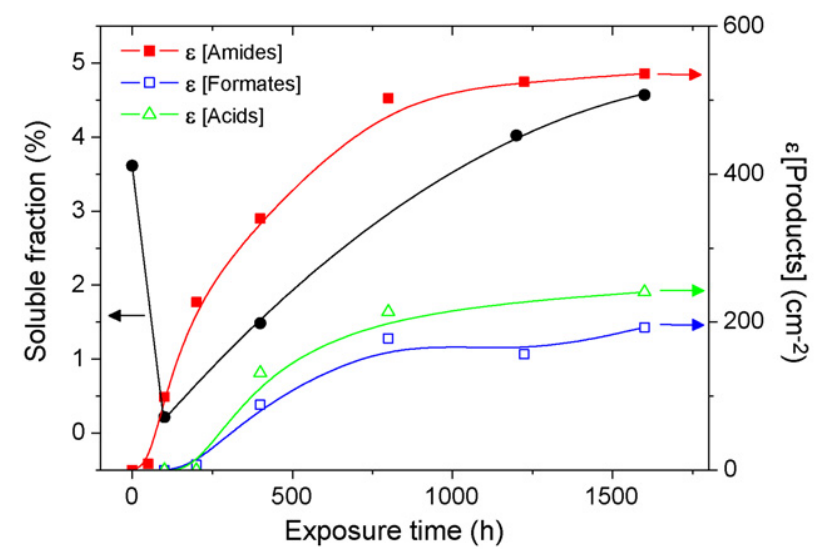

Fig. 12. Comparison between change of oxidation products concentration and soluble fraction during thermal ageing at $110^{\circ} \mathrm{C}$.

to the fact that hydroperoxides decomposition is, by far, the main radical chain initiation process [20]. All the other oxygen containing species display also an auto-accelerated character in the same timescale as amides. At short term, free films do not differ significantly from coatings on concrete (not shown). At long term, however, oxidation seems to be more auto-delayed in coatings than in films, but the difference can also be due to differences in sampling.

Kinetic curves of amide growth during irradiation are shown in Fig. 10. For most of the species under study, the concentration changes are on this side of the sensitivity limit of the method. For amides, however, one can observe a quasi linear growth at an approximate rate of $1.5 \times 10^{-4} \mathrm{~mol} \mathrm{l}^{-1} \mathrm{~h}^{-1}$ corresponding to a yield of about $6 \times 10^{-7}$ moles of amides per Gy.

\subsection{Physical modifications}

The changes of glass transition temperature $T_{g}$ during thermal ageing of samples coated on concrete are shown in Fig. 11a.

$T_{g}$ increases first during an initial period of the order of $400-500 \mathrm{~h}$ at $110^{\circ} \mathrm{C}$, about $1500 \mathrm{~h}$ at $90^{\circ} \mathrm{C}$, at least $3000 \mathrm{~h}$ at $70^{\circ} \mathrm{C}$ and more than $5000 \mathrm{~h}$ at $50^{\circ} \mathrm{C}$. The rate of $T_{g}$ rise is an increasing function of the temperature. Exposure in nitrogen atmosphere leads to the same $T_{g}$ increase (within experimental uncertainties) as in air (Fig. 11b). This result, and the fact that the rate of $T_{g}$ increase is maximum during the induction period of oxidation, clearly indicates that the crosslinking process responsible for $T_{g}$ increase is not due to oxidation. It is obviously a post-cure process linked to the presence of unreacted epoxide and amine groups
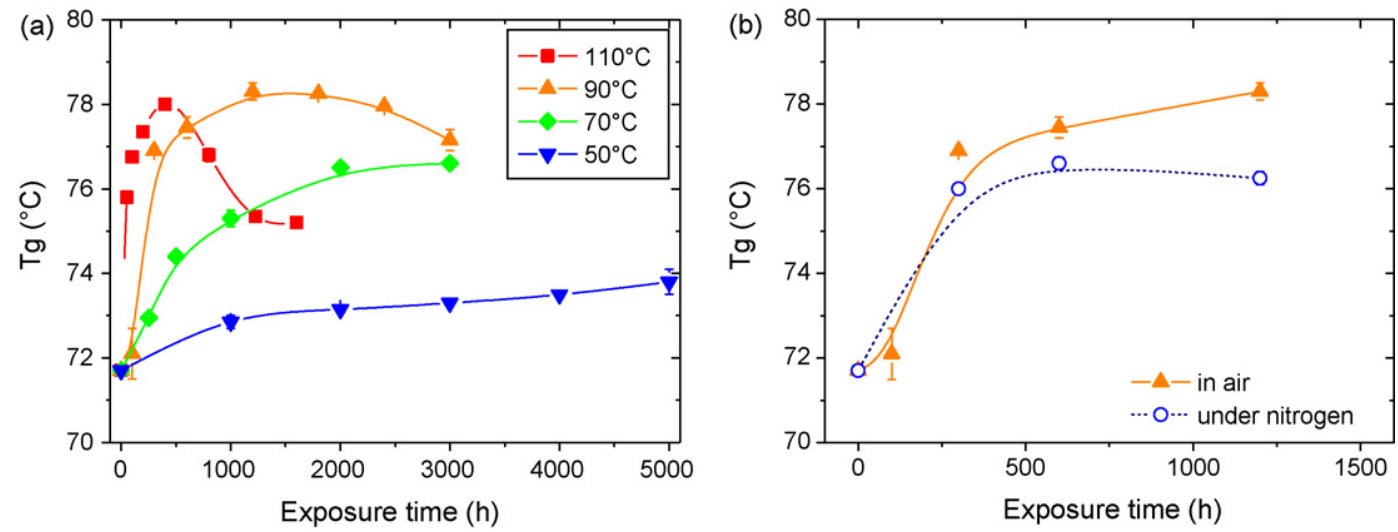

Fig. 11. Change of $T_{g}$ as a function of exposure time in air at 50,70, 90 and $110^{\circ} \mathrm{C}(\mathrm{a})$; in air and under nitrogen at $90{ }^{\circ} \mathrm{C}(\mathrm{b})$. 

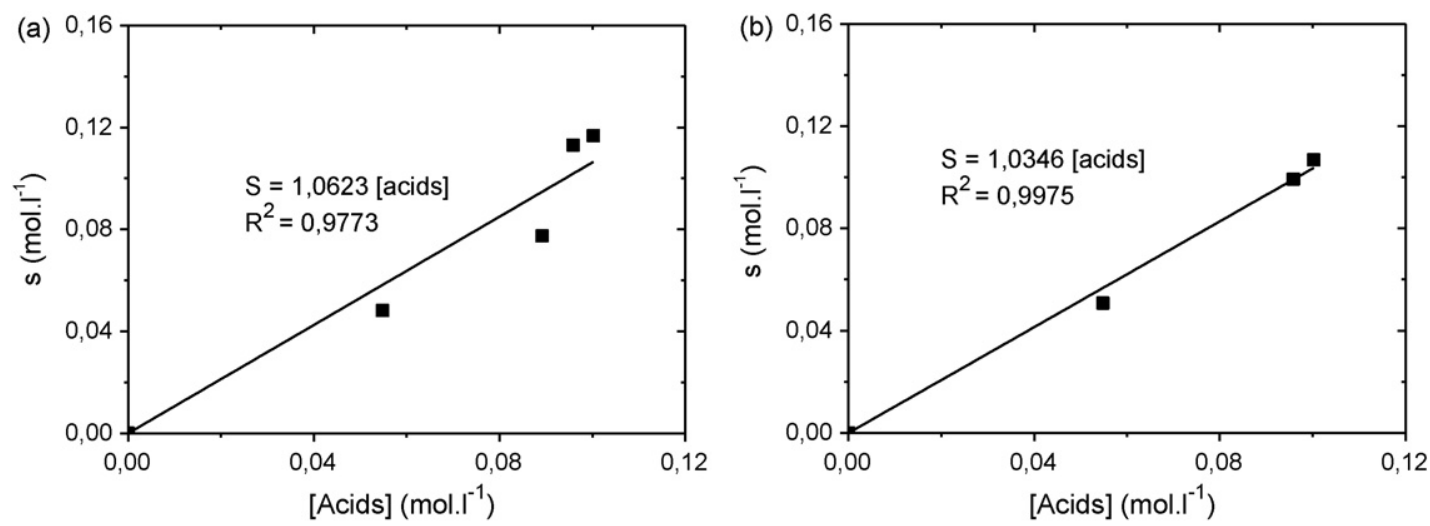

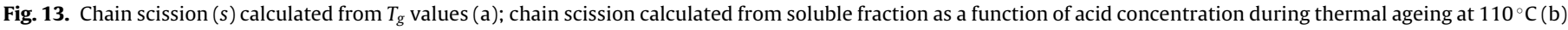

in the unaged samples. Indeed, the rate of post-cure is expected to decrease with the consumption of reactive groups and $T_{g}$ must tend towards an asymptotic value corresponding to the fully cured network. Here, however, $T_{g}$ decreases at more or less long term, that can be attributed to an oxidative degradation process. Degradation occurs after the end of the induction period, as expected from the build-up of oxidation products such as formates or acids, resulting from chain scissions. As expected, the soluble fraction decreases in the initial period where crosslinking predominates and increases at long term when chain scission predominates (Fig. 12). In the latter period, it can be tried to estimate the number $\mathrm{s}$ of chain scissions per mass unit from $T_{g}$ values, using Di Marzio's relationship [21,22]:

$s=\frac{T_{g l}}{2 K F}\left(\frac{1}{T_{g}(t)}-\frac{1}{T_{g \infty}}\right)$

where $T_{g \infty}$ is the $T_{g}$ of the fully cured network and $T_{g}(t)$ is the $T_{g}$ of the network having undergone s chain scissions. According to Bellenger et al. [23,24]: $K=2.91, F=18.9 \mathrm{~g} / \mathrm{mol}$ and $T_{g l}=329 \mathrm{~K}$.

The number of chain scissions determined by this method has been plotted against acid concentration in Fig. 13a. Both quantities are almost proportional with a ratio close to unity.

It has been also tried to determine the number of chain scissions from the soluble fraction (sol) using the Charlesby-Pinner equation [25]:

$\frac{v}{v_{0}}=\left(\frac{1-\operatorname{sol}^{1 / 2}}{1-\operatorname{sol}_{0}^{1 / 2}}\right)^{2}$

where $v_{0}$ and $v$ are the concentrations of elastically active chains, respectively, before and after ageing, whereas sol $_{0}$ and sol are the corresponding soluble fractions. Here $v_{0}=1.08 \mathrm{~mol} \mathrm{~kg}^{-1}$ and $\mathrm{sol}_{0}=2 \times 10^{-3}$.

In a network with trifunctional nodes, each chain scission leads to the disappearance of 3 elastically active chains:

$v=v_{0}-3 s$

So that:

$s=\frac{\nu_{0}}{3}\left(1-\left(\frac{1-\mathrm{sol}^{1 / 2}}{1-\operatorname{sol}_{0}^{1 / 2}}\right)^{2}\right)$

From the data of Fig. 12, $s$ values have been calculated and plotted against acid concentration in Fig. 13b. The results are in remarkable agreement with those of $T_{g}$ measurements.

\section{Conclusion}

This article deals with thermal and radiochemical ageing of an epoxy (DGEBA)-polyamidoamine network used as a polymeric base in coatings for nuclear plants. The results of IR spectrophotometric, DSC and sol-gel measurements lead to the following conclusions:

1) Post-cure reactions predominate in an initial period of which the duration is a decreasing function of the temperature of exposure. In the case under study, the maximum increase of $T_{g}$ was about $6^{\circ} \mathrm{C}$ but it can vary, indeed, with the initial state of cure and with the temperature $T$ of exposure. When $T$ is significantly lower than the initial $T_{g}$ value (which is the case here for the ageing temperature of $50^{\circ} \mathrm{C}$ ), post-cure is expected to be very slow and oxidative degradation can become predominant before the full cure has been achieved.

2) Oxidative degradation always predominates at long term. It is a very complex process owing to the diversity of oxidizable sites in such networks. However, tertiary amides appear as the major oxidation products, as well in thermal as in radiochemical ageing. It can be concluded that methylenes adjacent to tertiary amines (e.g. crosslinks) are especially reactive to oxidation that agrees with previously established structure-reactivity relationships.

3) Other oxygen containing species are formed in concentrations significantly smaller than amides, and with a yield significantly lower for radiochemical ageing than for thermal ageing (in the conditions under study). Despite their relatively lower concentration, certain of these species, especially acids, peracids or formates reveal the key role of the reactions responsible for their formation since they are necessarily chain scissions, having consequences on physical properties.

4) The occurrence of oxidative chain scissions is confirmed as well from $T_{g}$ measurements as from sol-gel analysis. Both methods indicate that there is about one acid group per chain scission. It is difficult at this state of our knowledge to determine the part of epoxide and diamine moieties in this process. Understanding the mechanism of chain scission is crucial because embrittlement is mainly caused by this process. Experiments on well defined model systems would probably allow describing more precisely these processes.

\section{References}

[1] N. Khelidj, X. Colin, L. Audouin, J. Verdu, Nucl. Instr. Methods Phys. Res. B136 (2005) 88-99.

[2] J.T. Morgan, G. Scott, R. Sheldon, G.B. Stapleton, Rutherford Laboratory Report RHEL/R 196, 1970, pp. 1-30. 
[3] S.G. Burnay, Radiat. Phys. Chem. 16 (1980) 389-397.

[4] S.G. Burnay, Radiat. Phys. Chem. 19 (1982) 93-99.

[5] V. Bellenger, J. Verdu, J. Appl. Polym. Sci. 30 (1985) 363-374.

[6] Y. Ngono, Y. Marchal, N. Mermillod, J. Phys. Chem. B103 (1999) 4979-4985

[7] D.E. Kline, J.E. Sauer, SPE Trans. (January) (1962) 21-24.

[8] T. Sasuga, A. Udagawa, Polymer 32 (1991) 402-408.

[9] L. Vignoud, L. David, B. Sixou, G. Vigier, Polymer 42 (2001) 4657-4665.

[10] T. Devanne, A. Bry, L. Audouin, J. Verdu, Polymer 46 (2005) 229-236.

[11] J.S. Park, K.S. Seo, R.E. Fornes, R.D. Gilbert, Plast. Rubber. Process. Appl. 10 (1988 203-209.

[12] N. Longerias, M. Sebban, P. Palmas, A. Rivaton, J.L. Gardette, Polym. Degrad. Stab. 92 (2007) 2190-2197.

[13] B. Mailhot, S. Morlat-Thérias, M. Ouathioune, J.L. Gardette, Macromol. Chem. Phys. 2006 (2005) 575-584.

[14] B. Dao, J. Hodgkin, J. Kristina, J. Mardel, W. Tran, J. Appl. Polym. Sci. 102 (2006) 3221-3232.
[15] P. Musto, G. Ragosta, P. Russo, L. Mascia, Macromol. Chem. Phys. 202 (2001) 3445-3458.

[16] J.R. Lee, S.J. Park, M.K. Seo, Y.K. Baik, S.K. Lee, Nucl. Eng. Des. 236(2006) 931-937.

[17] C. Laurence, M. Helbert, A. Lachkar, Can. J. Chem. 71 (1993) 254

[18] A. Rivaton, L. Moreau, J.L. Gardette, Polym. Degrad. Stab. 58 (1997) 321-332.

[19] E.T. Denisov, I.B. Afanas'ev, Oxidation and Antioxidants in Organic Chemistry and Biology, CRC Taylor \& Francis group Ed., 2005.

[20] A.V. Tobolsky, D.J. Metz, R.M. Mesrobian, J. Am. Chem. Soc. 72 (1950) 1942-1952.

[21] E.A. Di Marzio, J. Res. NBS 68A (1964) 611.

[22] T. Devanne, A. Bry, N. Raguia, M. Sebban, P. Palmas, L. Audouin, J. Verdu, Polymer 46 (2005) 237-242.

[23] V. Bellenger, E. Morel, J. Verdu, J. Polym. Sci. Polym. Phys. Ed B25 (1987) 1219-1234.

[24] V. Bellenger, E. Morel, J. Verdu, J. Mater. Sci. 23 (1988) 42-44.

[25] A. Charlesby, S.H. Pinner, Proc. Roy. Soc. Lond. A 249 (1961) 367. 